\title{
¿Estamos todos de acuerdo con la Asignación Universal por Hijo? Entre el liberalismo y la recuperación del Estado*
}

\author{
Torrice Lucas Javier**
}

\section{Resumen}

En el presente trabajo propongo exponer descriptivamente algunas herramientas conceptuales que nos posibiliten comprender el actual consenso de todo el espectro político en torno a una política social como la Asignación Universal por Hijo (AUH). Se buscará reconstruir los contextos y antecedentes de la AUH y las diversas justificaciones que se pueden encontrar en distintas tradiciones teórico-políticas. Desde distintos posicionamientos ideológicos se puede brindar un consentimiento a la $\mathrm{AUH}$, así sea vista únicamente como una política de asistencia focalizada en los grupos más vulnerables para paliar la pobreza, como que se la valore como un piso de ingresos que apunta a garantizar un ingreso "universal" para la niñez. La propuesta es recuperar aportes de algunos clásicos del pensamiento político para matizar las diversas miradas que existen sobre la $\mathrm{AUH}$. Este trabajo busca introducir de forma expositiva algunos conceptos que están en las diversas tradiciones que conforman los actuales debates sobre las políticas sociales de combate a la pobreza en América Latina,

\footnotetext{
* Artículo recibido el 4 de Abril de 2016. Aceptado el 26 de Julio de 2016.

** Licenciado en Trabajo Social. Becario de SeCyT UNC. Miembro de la cátedra Políticas Sociales del Estado. Facultad de Ciencias Sociales Universidad Nacional de Córdoba. Lucas_1148@hotmail.com
} 
De Prácticas y discursos/ Universidad Nacional del Nordeste/ Centro de Estudios Sociales

introducción que creemos pertinente en la búsqueda de mejores respuestas frente a la desigualdad social que caracteriza a nuestra región.

\section{Palabras clave}

Asignación Universal por Hijo-Políticas sociales-Disputas de sentido.

\section{Abstract}

In this paper I propose to present some conceptual tools that enable us to understand the current consensus across the political spectrum around a social policy such as the Universal Child Allowance (AUH). It will seek to reconstruct the context and background of the AUH and the various justifications that can be found in different theoretical and political traditions. From different ideological positions you can provide consent to the $\mathrm{AUH}$, whether seen only as an attendance policy focused on the most vulnerable groups to alleviate poverty, as they value it as an income floor that aims to ensure a "universal income "for children. The proposal is to recover contributions of some classics of political thought to qualify the different looks that exist on the AUH. This paper seeks to introduce so expository some concepts that are in the various traditions that make up the current debates on social policies to combat poverty in Latin America, introduction we believe relevant in the search for better answers to address social inequality.

\section{Keywords}

universal child allowance-Social politics-Dispute sense.

\section{Introducción}


La Asignación Universal por $\mathrm{Hijo}^{1}$ es una política social de jurisdicción nacional que mediante el Decreto presidencial 1.602 de 2009 incorpora este beneficio al Artículo 1 de la ley 24.714, concerniente al Régimen Nacional de Asignaciones Familiares. La misma amplía la cobertura del acceso a asignaciones familiares en un sistema no contributivo que incluye a los trabajadores desocupados, monotributistas sociales y trabajadores informales que perciban un ingreso inferior al salario mínimo, vital y móvil, y empleadas/os del servicio doméstico. Posteriormente, también incluyó a los trabajadores de temporada o con reserva de puesto de trabajo y a personas privadas de su libertad que se encuentran procesadas y que desempeñan tareas dentro de las Unidades del Servicio Penitenciario Federal. Dicha política establece un pago mensual por hijo/a e hijo/a discapacitado/a a los padres de menores de 18 años -sin límite de edad para los hijos discapacitados-. El monto es el mismo que la asignación familiar por hijo comprendida en el régimen contributivo vigente. En 2011 además se incorpora la asignación por embarazo para la protección social. El 15 de julio de 2015, se sancionó la ley 27.160 que establece la movilidad del monto de las asignaciones familiares, incluyendo la AUH. La AUH exige como condicionalidad ${ }^{2}$ certificados

\footnotetext{
${ }^{1}$ En un balance de ejecución de la política a finales de 2011, la ANSES informa que 3,5 millones de niños y 1,8 millones de hogares en todo el país accedieron a la AUH. La mayor parte de los titulares se concentra en la franja etárea entre los 30 y los 34 años. Del total, el 94,4\% son mujeres, es decir que son las madres/tutoras las que administran casi la totalidad de las asignaciones. Puesto que al inicio de la medida las mujeres representaban el $78 \%$ de los adultos responsables, el informe atribuye en parte la feminización de la titularidad a la normativa dispuesta por ANSES en su Resolución 393/09, que establece en su Artículo 10 que "cuando la tenencia del niño, adolescente o persona discapacitada sea compartida por ambos padres, la madre tendrá prelación sobre el padre en la titularidad de la prestación" (ANSES, 2012:30).

2 El texto del Decreto 1.602/09 sostiene: "e) Hasta los CUATRO (4) años de edad -inclusive-, deberá acreditarse el cumplimiento de los controles sanitarios y del plan de vacunación obligatorio. Desde los CINCO (5) años de edad y hasta los DIECIOCHO (18) años, deberá acreditarse además la concurrencia de los menores obligatoriamente a establecimientos educativos públicos. f) El titular del beneficio deberá presentar una declaración jurada relativa al cumplimiento de los requisitos exigidos por la presente y a las calidades invocadas, de comprobarse la falsedad de algunos de estos datos, se producirá la pérdida del beneficio, sin perjuicio de las sanciones que correspondan.

ARTICULO $7^{\circ}$.- Incorpórase como inciso k) del artículo 18 de la Ley $N^{\circ} 24.714$ y sus modificatorios: "inciso k) Asignación Universal por Hijo para Protección Social: la mayor suma fijada en los incisos a) o b), según corresponda.

EI OCHENTA POR CIENTO (80\%) del monto previsto en el primer párrafo se abonará mensualmente a los titulares de las mismas a través del sistema de pagos de la ADMINISTRACIÓN NACIONAL DE LA SEGURIDAD SOCIAL (ANSES). El restante VEINTE POR CIENTO (20\%) será reservado en una Caja de Ahorro a nombre del titular en el BANCO DE LA NACIÓN ARGENTINA percibido a través de tarjetas magnéticas emitidas por el banco, sin costo para los beneficiarios. Las sumas podrán cobrarse cuando el titular acredite, para los menores de CINCO (5) años, el cumplimiento de los controles sanitarios y el plan de
} 
De Prácticas y discursos/ Universidad Nacional del Nordeste/ Centro de Estudios Sociales

periódicos de salud y educación de los/as niños/as titulares de la misma, dichos certificados se registran en una libreta que está a cargo del tutor del niño/a.

Por su historia previa, por las políticas sociales que la antecedieron y por el propio diseño institucional de la $\mathrm{AUH}$, se reconoce una tensión intrínseca entre visiones que la asocian a la seguridad social y otras a la asistencia social. Esta tensión está presente en los numerosos análisis que existen sobre la $\mathrm{AUH}$, que buscan debatir sobre las recientes transformaciones en las políticas sociales en general y en la seguridad social en particular.

Respecto de esta tensión, comenzamos precisando que la asistencia y la seguridad social se inscriben en tradiciones (en historias) diferentes: la primera, organizada en torno al principio de la necesidad, fuertemente vinculada con las características de la persona y de su situación; la segunda, en cambio, referenciada en el reconocimiento de derechos: acotados, estratificados y segmentados en muchos casos, pero sus sujetos (por lo general, trabajadores asalariados formales) pueden invocar esa condición como fuente de derechos. (Costa y Hintze, 2014: 244-245).

Actualmente, nutridos debates académicos se propician en torno a la AUH. Los ejes principales giran en relación con la naturaleza de estos cambios, al grado de universalidad y a la presencia de condicionalidades, entre otros aspectos. Diversos análisis arriban a conclusiones diferentes según como son interpretados los distintos elementos que componen la historia y la actualidad de la AUH y de las políticas sociales. Algunos reconocen, por un lado, un avance de la asistencia hacia un estatuto de derechos. Por otro lado, se plantea, de manera menos optimista, que el proceso podía ser interpretado como una asistencialización de la seguridad social.

Esta tensión se manifiesta, entre otras cosas, en que la AUH reemplaza los Programas de Transferencia Condicionada de Ingresos (PTCI) nacionales más importantes -Plan 
De Prácticas y discursos/ Universidad Nacional del Nordeste/ Centro de Estudios Sociales

jefes y jefas de hogar desocupados y el programa Familias por la inclusión social-. A pesar de la permanencia de condicionalidades -en salud y educación-, los elementos endógenos de la AUH y las transformaciones que la antecedieron -las reformas en la seguridad social- como las que luego fueran surgiendo -inclusión de programas como Conectar Igualdad, PROGRESAR, programa de salud SUMAR, entre otros- remiten a una serie de particularidades que indica un cambio de paradigma. Existe un amplio consenso vinculado a que la seguridad social en general, y la ANSES en particular, se encuentra hoy en el centro de la política social y ha sido en el último tiempo un motor en la redistribución del ingreso.

Este giro de paradigma que se le reconoce desde algunas posiciones a la AUH se basa en reconocer como un nuevo sujeto de derechos al trabajador informal históricamente excluido de los beneficios de la seguridad social. Se diferencia de las políticas predominantes en los años noventa que marcaban fuertemente la separación entre trabajadores y pobres sobre la base de una marcada distinción entre políticas del seguro y políticas de asistencia (González, 2012). También se destaca la pretensión de universalidad en la amplia cobertura que supone y la importancia del monto transferido reflejado en su participación en el presupuesto nacional y sus impactos en la reducción del hambre y la indigencia. A su vez, supone un cambio de paradigma en cuanto a las políticas sociales de la niñez, dando un salto cualitativo hacia una protección ampliada de la infancia (Mazzola, 2012), cumpliendo con el espíritu de la ley 26.061 de protección integral de la niñez.

Como forma de transferir ingresos a las familias más desafiliadas socialmente se reconoce que se eleva el piso de ingresos transformando notablemente la capacidad de consumo de los sectores populares. En este sentido, el diseño y la operatividad institucional aportan previsibilidad. Siendo la magnitud del ingreso, la transferencia directa de los recursos - sin mediaciones discrecionales- y una proyección a largo plazo de las prestaciones, un apoyo sustancial a las estrategias de reproducción cotidiana de la existencia de las familias (Torrice e Iriarte, 2014). 
Algunos elementos contextuales que están presentes en las interpretaciones sobre la AUH y que definen los posicionamientos son:

- Desde mediados de los noventa se inició un debate en torno a propuestas de universalización del ingreso ciudadano. Se plantearon iniciativas ligadas a la universalización de las asignaciones familiares o a la implementación de un Ingreso Ciudadano a la Niñez (Lo Vuolo y otros, 1995). Se destacan las actividades de la Red Argentina de Ingreso Ciudadano -REDAIC- o la CTA que en el 2000 daba impulso a la propuesta a través del Frente Nacional contra la Pobreza (FRENAPO) ${ }^{3}$ y desde entonces realizó diversas acciones a su favor (Arcidiácono y otros, 2011).

- Central para entender los cambios acontecidos en la última década fue la crisis y estallido social del 2001 y 2002. Como consecuencia de la crisis del modelo neoliberal con una insostenible propagación de hambre y desocupación, comienza a darse un leve giro político e ideológico en el tratamiento de la pobreza donde el Estado comienza a asumir parte de su responsabilidad en el mejoramiento de esas situaciones.

- Ligado a lo anterior, surge el auge nacional y regional de los $\mathrm{PTCI}^{4}$, avalados y financiados por organismos internacionales como el BID y el Banco Mundial. Supone asumir públicamente que el mercado no resuelve por sí solo la pobreza, sino que el

\footnotetext{
${ }^{3}$ La propuesta del FRENAPO suponía tres medidas complementarias: 1. Seguro de Empleo y Formación para todos los Jefes de Hogar Desocupados, 2. la universalización del haber mínimo para los mayores y la universalización de las asignaciones familiares a través de un complemento que alcanzaría a todos los excluidos del sistema de AAFF para trabajadores formales. Ver: Instituto de Estudios y Formación, CTA (La propuesta de la CTA en la Marcha Grande por el trabajo. Por un Seguro de Empleo y Formación para los Jefes de Hogar Desocupados. Página 12, Argentina, 2000).

${ }^{4}$ Las principales críticas a estas políticas son, por un lado, que éstas denominan a sus receptores en términos de "necesitados" o "pobres", y no de ciudadanos con derechos; lo cual produce procesos de estigmatización, a la vez que socava los cimientos de la ciudadanía al construir jerarquías de ciudadanos de primera y de segunda clase. Por otro lado, la exigencia de ser "carenciado" para ser receptor, no solo estigmatiza, sino que genera, como consecuencia no deseada, la reproducción de la "trampa de pobreza", al estimular la perdurabilidad de las personas en esa situación. Finalmente, las políticas focalizadas presentan severos límites para llegar a cubrir a todos los habitantes que cuentan con las condiciones para ser "beneficiarios" (incluso en estos términos estigmatizantes), lo que da cuenta de que los criterios de selección están permeados de un cierto grado de arbitrariedad que acentúa las desigualdades (Arcidiácono y otros, 2011).
} 
Estado debe intervenir de manera activa para mitigarla. Predominaba una lógica liberal de la asistencia, de carácter residual y focalizado, desvinculado del mercado de trabajo y notablemente estigmatizante con la población beneficiaria a la cual no se la consideraba como sujeto de derecho.

- Más cercano en el tiempo, desde el 2003 surge una serie de modificaciones al interior del sistema previsional fruto del inicio de un nuevo ciclo político post neoliberal ${ }^{5}$, donde comienza a recuperarse la centralidad del Estado en la intervención social, marcado por un activismo del Ejecutivo nacional en la sanción de normativas y programas contrarios a la lógica hegemónica de la década anterior. Hacia comienzos de 2005, mediante la ley 25.944 se flexibilizaron las condiciones de acceso a las prestaciones previsionales y se fijó una prestación de jubilación anticipada para aquellas personas que cumplían con los años de aportes para acceder al beneficio previsional, pero no con la edad de retiro. Además, por medio del establecimiento de una moratoria provisional, se permitió a los trabajadores autónomos -o a sus derechohabientes- que no cumplían con los años de aportes acceder a los beneficios previsionales. La moratoria de 2005 tuvo como objetivo ampliar la cobertura facilitando el acceso al sistema de quienes se hallaban excluidos por la vía de suavizar los requisitos contributivos. Luego, en 2008, se crea el Sistema Integrado Previsional Argentino (SIPA), a través de la ley 26.425. Esta normativa implica la eliminación de las administradoras privadas basadas en la capitalización individual y el paso de sus fondos al sistema único de reparto. Se recupera plenamente el rol estatal y las nociones de solidaridad intergeneracional para garantizar el funcionamiento del sistema y la inclusión de los sectores más

\footnotetext{
${ }^{5}$ Algunas autoras como Danani y Beccaria (2011) consideran estas transformaciones como una contra reforma del sistema previsional con respecto a las modificaciones introducidas en los noventa bajo el modelo neoliberal. La reforma del sistema previsional de la década del noventa combinaba todas las tendencias del modelo neoliberal tales como: la privatización institucional, la individualización del principio de protección y el rol subsidiario del Estado con respecto al funcionamiento de los mercados con la articulación del sistema alrededor del capital financiero y las entidades que funcionaban como agentes. En efecto, la reforma materializada en la ley $24.241 / 93$ crea un mercado donde hasta entonces no existía y desmonta lo que era el mecanismo de relativa confluencia de intereses entre distintas generaciones de trabajadores -activos y pasivos-. Se dan dos grandes transformaciones: la transposición del "trabajadorsujeto de derecho" en "individuo ahorrador titular de una cuenta", y la pretensión de remplazar la solidaridad del trabajo como motor de afiliación social por el interés y la ganancia (Danani; Grassi, 2008).
} 
desfavorecidos. En ese mismo año, por medio de la Ley de Movilidad (ley 26.417), se sanciona que la actualización de las prestaciones, que hasta ese entonces se había realizado de manera diferenciada por tramos de haberes, pasara a realizarse de manera uniforme, cada seis meses y a partir de parámetros predeterminados relacionados con la evolución de los salarios de los trabajadores en actividad y de los recursos previsionales-. En 2009 se crea la AUH, y en 2011 se incorpora la asignación por embarazo para la protección social. Posteriormente, en agosto de 2014, mediante la ley 26.970 se impulsa una nueva moratoria previsional que busca lograr la universalización de la cobertura de jubilaciones alcanzando al 97\% de la población en edad de acceder. Recientemente, el 15 de julio, se sancionó la ley 27.160 que establece la movilidad del monto de las asignaciones familiares, incluyendo la $\mathrm{AUH}$.

- Por último, es menester mencionar la crisis internacional de 2008 con epicentro en las potencias mundiales ${ }^{6}$ que condujo al Ejecutivo nacional a tomar medidas de carácter anticíclicas y fortalecer el mercado interno y el consumo popular. Las mayores transformaciones y conquistas de nuevos derechos se produjeron en el segundo mandato de Cristina Fernández de Kirchner.

Según como se interpreten las transformaciones de la última década y la crisis del modelo neoliberal, es que se juzgará a la AUH entre la seguridad social y la asistencia. Por estos motivos, distintos autores sostienen que la AUH conserva su caracterización como PTCI (Pautassi, 2012). Otros como Lo Vuolo (2010) resaltan el carácter de "hibridez" de la AUH con respecto a estos dos aspectos. Por el contrario, algunos escritores rescatan el avance en términos de la seguridad social y los nuevos derechos que supone (Tirenni,2013), diferenciándola tajantemente de las políticas anteriores.

\footnotetext{
${ }^{6}$ Es conocida la secuencia de la crisis internacional: crisis de las subprimes (agosto de 2007), quiebra de Lehman Brothers (septiembre de 2008) y luego de otras instituciones bancarias, destrucción masiva de activos, recesión mundial, pérdida de 30 millones de empleos, aumento de la pobreza y la desigualdad. (Baschet, 2014).
} 
De Prácticas y discursos/ Universidad Nacional del Nordeste/ Centro de Estudios Sociales

Para dar un paso más en la discusión, propongo recuperar los aportes conceptuales de Esping-Andersen (1993), considerado un clásico en el estudio de las políticas sociales. El autor sostiene que en las políticas sociales la disputa ideológica se presenta como una disputa sobre modelos de distribución del bienestar. En este sentido, compiten distintos modos de comprender la intervención estatal, al papel del mercado y la familia como instituciones proveedoras del mismo. Ordenamientos cualitativamente distintos entre el grado y la forma de intervención que tengan el Estado, el mercado y las familias conducen a la conformación de diversos regímenes de bienestar. En este sentido, el Estado de Bienestar no es solo un mecanismo que interviene en la estructura de la desigualdad intentando corregirla, es un sistema de estratificación en sí mismo, es una fuerza activa en el ordenamiento de las relaciones sociales. Vinculado a esto, autores como Danani no consideran a la política social como mera reacción del Estado a la cuestión social o a la cuestión obrera, sino como la forma estatal de construir tales cuestiones; como un momento de máxima actividad estatal en la regulación y conformación de patrones diferenciados de reproducción social (1996).

Esping-Andersen define tres modelos o regímenes de bienestar. Por un lado, el Estado de Bienestar "liberal", donde predominan la ayuda a los que se comprueba que no tienen medios y los planes modestos de seguros sociales. Las reglas para acceder a estos derechos son estrictas y a menudo están asociadas a un estigma. A su vez, el Estado estimula el mercado pasiva o activamente. Este tipo de régimen minimiza los efectos de la desmercantilización, limitando el alcance de los derechos sociales, y construye un orden de estratificación, que es una mezcla de una relativa igualdad de pobreza entre los beneficiarios de la protección social, de un bienestar social para mayorías diferenciado por el mercado.

Por otro lado, encontramos el Estado de Bienestar "corporativo", que implica a Estados conservadores, donde predominó la conservación de las diferencias de status. Los derechos fueron vinculados a la clase y al status social. El impacto del Estado en la redistribución es insignificante. Por lo general, estos regímenes están conformados por 
De Prácticas y discursos/ Universidad Nacional del Nordeste/ Centro de Estudios Sociales

la Iglesia y, por eso, están fuertemente comprometidos con la conservación de la familia tradicional. Por ello, aparece el Estado como subsidiario en la intervención, solamente cuando se acabe la capacidad de la familia para atender a sus miembros.

Por último, los regímenes "socialdemócratas", el principio del universalismo y la desmercantilización de los derechos sociales se han extendido a las nuevas clases medias. Buscan un Estado que promueva una igualdad de los estándares más elevados, no una igualdad en las necesidades mínimas. Esto implicaba que los servicios y prestaciones se elevaran hasta niveles equiparables con los gustos de la nueva clase media y que la igualdad se proporcionaría garantizando a los obreros la completa participación en la calidad de los derechos disfrutados por lo más pudientes. El principio es socializar prioritariamente los costes de la familia. El resultado es un estado de bienestar que suministre las prestaciones directamente a los niños y que se responsabilice claramente también de los ancianos y los necesitados; a la vez que este régimen está obligado a garantizar al mismo tiempo el pleno empleo y a depender enteramente de su logro.

Estos regímenes de bienestar no existen en forma pura, los distintos Estados suelen combinar distintamente elementos de los tres. Por lo tanto, encontraremos elementos residuales, corporativos y universales.

En lo que sigue propongo agrupar los aportes teóricos que considero relevantes para la discusión en tres bloques. Por un lado, algunos aspectos presentes en el liberalismo clásico y posteriormente en el neoliberalismo. En un segundo momento, recupero la influencia de Rousseau y Marx para las tradiciones de izquierda. Aquí incluyo los debates sobre el Ingreso Ciudadano y los actuales aportes de lo que se conoce como enfoque de derechos humanos. Por último, se considera la recuperación de la centralidad del Estado y las ideas de Hegel que contribuyen a comprender esto. No se propone un análisis exhaustivo de las distintas corrientes teóricas e ideológicas, más bien se busca apelar a diversos elementos conceptuales que permitan una mayor 
De Prácticas y discursos/ Universidad Nacional del Nordeste/ Centro de Estudios Sociales

comprensión de las distintas posturas que están en disputa frente a las actuales discusiones de la política social argentina.

\section{Una mirada desde el liberalismo}

Siendo el liberalismo la doctrina política que defiende las libertades y la iniciativa individual, y que se preocupa por limitar la intervención del Estado y de los poderes públicos en la vida social, económica y cultural, se podría pensar que desde este punto de vista se resaltaría la potencialidad de la AUH para garantizar la autonomía de las personas y la liberación de sus capacidades creativas.

Al pensar en términos de justicia social, el liberalismo quiere menos reducir las desigualdades existentes entre las diferentes posiciones sociales que luchar contra las discriminaciones que perturbarían una competencia al término de la cual los individuos, iguales en el punto de partida, ocuparían posiciones jerarquizadas. Las desigualdades son consideradas en la medida que resultan obstáculos que se oponen al desarrollo de una competencia equitativa (Dubet, 2014).

Los liberales clásicos todos estaban de acuerdo en que el camino hacia la prosperidad de la sociedad llegaría a partir de contar con el máximo de libertad de mercado y el mínimo de interferencia estatal. Su adopción entusiasta del capitalismo de mercado puede parecer ahora injustificada. Pero no debemos olvidar que la realidad de la que hablaban era la de un Estado que apoyaba privilegios absolutistas, el proteccionismo mercantilista y una corrupción generalizada. Lo que ellos atacaban era un gobierno que reprimía sus ideales tanto de libertad como de iniciativa privada.

John Stuart Mill (1806-1873), uno de los autores más relevantes del liberalismo del siglo XIX, escribió en 1859 su libro Sobre la libertad. En él se dirige a la naturaleza y los límites del poder que puede ser ejercido legítimamente por la sociedad sobre el individuo. Busca encontrar los fundamentos que separan la libertad individual y el 
De Prácticas y discursos/ Universidad Nacional del Nordeste/ Centro de Estudios Sociales

control social. A su vez, buscó defender la libertad social de lo que denominó la "tiranía de las mayorías".

Mill sostenía allí que: "La única libertad que merece este nombre es la de buscar nuestro propio bien a nuestra propia manera, en tanto que no intentemos privar de sus bienes a otros, o frenar sus esfuerzos para obtenerla. Cada cual es el mejor guardián de su propia salud, sea física, mental o espiritual. La especie humana ganará más en dejar a cada uno que viva como le guste más, que en obligarle a vivir como guste al resto de sus semejantes".

A su vez, propone un principio "encaminado a regir de modo absoluto la conducta de la sociedad en relación con el individuo". Tal principio sería el siguiente: "el único objeto, que autoriza a los hombres, individual o colectivamente, a turbar la libertad de acción de cualquiera de sus semejantes, es la propia defensa; la única razón legítima para usar de la fuerza contra un miembro de una comunidad civilizada es la de impedirle perjudicar a otros; pero el bien de este individuo, sea físico, sea moral, no es razón suficiente" (Mill, 2004:26).

Seguidamente, plantea una salvedad a estos principios que me parece importante destacar: "Apenas si es necesario decir que esta doctrina no alcanza más que a los seres humanos que se hallen en la madurez de sus facultades. No hablamos de niños ni de jóvenes de ambos sexos que no hayan llegado al tope fijado por la ley para la mayoría de edad. Aquellos que están en edad de reclamar todavía los cuidados de otros, deben ser protegidos, tanto contra los demás, como contra ellos mismos" (Mill, 2004:27). De esta manera, se restringe la idea de libertad para las personas mayores de edad y se habilita la posibilidad de brindar protección a los menores como medio para que alcancen la madurez necesaria para el ejercicio de su libertad.

Además, asegura que: "Si considerásemos que el libre desarrollo de la individualidad es uno de los principios esenciales del bienestar, si le tuviéramos, no como un elemento coordinado con todo lo que se designa con las palabras civilización, instrucción, 
De Prácticas y discursos/ Universidad Nacional del Nordeste/ Centro de Estudios Sociales

educación, cultura, sino más bien como parte necesaria y condición de todas estas cosas, no existiría ningún peligro de que la libertad no sea apreciada en su justo valor y no habría que vencer grandes dificultades en trazar la línea de demarcación entre ella y el control social. Pero, desgraciadamente, a la espontaneidad individual, no se le suele conceder, por parte de los modos comunes de pensar, ningún valor intrínseco, ni se la considera digna de atención por sí misma". "Este valor otorgado al libre desarrollo de la individualidad es la que justifica una protección de los niños y jóvenes para que puedan alcanzarla" (Mill, 2004:70).

A esto se vincula uno de los principales logros de la visión liberal de la igualdad de oportunidades en lo que refiere a la homogeneidad de la oferta escolar, y en considerar la igualdad de la oferta educativa como base de la justicia (Dubet, 2014).

Al mismo tiempo, la importancia de la educación para el desarrollo individual se vinculó en el liberalismo económico con las teorías del Capital Humano. Dichas teorías refieren a ciertas conceptualizaciones económicas del crecimiento para designar a un hipotético factor de producción dependiente no solo de la cantidad, sino también de la calidad, del grado de formación y de la productividad de las personas involucradas en un proceso productivo. LoS PTCI impulsados por organismos internacionales incluían justificaciones vinculadas a las teorías del capital humano. Si bien la teoría del capital humano nació fundamentalmente asociada al trabajador, su utilización en los estudios de pobreza amplió el espectro de su alcance explicativo (Straschnoy, 2015).

Aún en los principales teóricos del neoliberalismo es posible encontrar justificaciones conceptuales que avalan algún tipo de asistencia. Recordemos que este modelo conocido como neoliberalismo se basó en el achicamiento del Estado o "Estado mínimo", el recorte del gasto social, la privatización, la focalización del gasto social público y la descentralización (Laurell, 2000). 
De Prácticas y discursos/ Universidad Nacional del Nordeste/ Centro de Estudios Sociales

Por neoliberalismo se entiende mucho más que una política o un modelo económico, se constituye en una ideología, una representación del mundo, una cultura que define relaciones y acciones, modos de entender el lugar de la persona en el mundo y su modo de vida. Una propuesta íntegra de sociabilidad, en la que el mercado es mucho más que un principio de regulación, es presentado como el contorno y modelo mismo de la sociedad (Danani y Grassi, 2008). Se produce la influencia de un paradigma individual-competitivo, mostrando el pasaje de un modelo cultural relacionado a lo público-estatal de solidaridades nacionales hacia otro vinculado al mercado, a la sociedad civil y la competencia. La centralidad que adquiría el "trabajador" en el Estado de bienestar, en el neoliberalismo es asumida por el sujeto "consumidor" (García Delgado, 1994).

Robert Nozick, considerado como uno de los principales teóricos del neoliberalismo, es quien sentó algunas de sus bases filosóficas más difundidas. Su profundo rechazo al intervencionismo estatal desestima cualquier política social que tienda a la redistribución del ingreso. Un pensador como Nozick considera que la función del Estado debe restringirse a la protección de los intereses privados y que, por tanto, el Estado no debe intervenir mediante políticas redistributivas en este ámbito.

Las demandas por justicia social e igualdad política no deben interferir en el funcionamiento del mercado y de la propiedad privada. Mientras el Estado proteja esta propiedad, no se hace necesario que introduzca derechos adicionales como los económicos y los sociales, puesto que, por un lado, el aseguramiento de los derechos civiles lleva necesariamente a unas apropiadas condiciones de vida para todos y, por otro lado, la introducción de derechos económicos y sociales y su consecuente realización exige restringir la autonomía individual. De esta manera, limitar las libertades y derechos individuales para satisfacer una concepción redistributiva de justicia es injustificable moralmente para Nozick. Su Estado mínimo no debe ir más allá del aseguramiento de los derechos y libertades individuales. 
De Prácticas y discursos/ Universidad Nacional del Nordeste/ Centro de Estudios Sociales

El individualismo extremo de Nozick lo lleva a no admitir que a través de unas políticas redistributivas se tome parte de las ganancias laborales para asistir a otras personas: "El impuesto a los productos del trabajo va a la par con el trabajo forzado. Algunas personas encuentran esta afirmación obviamente verdadera: tomar las ganancias de $n$ horas laborales es como tomar $\mathrm{n}$ horas de la persona; es como forzar a la persona a trabajar $n$ horas para propósitos de otra. Para otros, esta afirmación es absurda. Pero aun éstos, si objetan el trabajo forzado, se opondrían a obligar a hippies desempleados a que trabajaran en beneficio de los necesitados, y también objetarían obligar a cada persona a trabajar cinco horas extra a la semana para beneficio de los necesitados. Sin embargo, no les parece que un sistema que toma el salario de cinco horas en impuestos obliga a alguien a trabajar cinco horas, puesto que ofrece a la persona obligada una gama más amplia de opción en actividades que la que le ofrece la imposición en especie con el trabajo particular, especificado" (Nozick, 1988:170-171).

Sin embargo, en otros autores neoliberales, como Hayek y Friedman, es posible encontrar algunos matices de estos planteos.

Friedrich A. Hayek (1899-1992), en su libro Camino a la servidumbre de 1944, reconoce, con muchas salvedades, un tipo de seguridad que es posible otorgar en las situaciones más severas. Se trata de una seguridad contra una privación material grave. Sostiene que: "No hay motivo para que una sociedad que ha alcanzado un nivel general de riqueza como el de la nuestra, no pueda garantizar a todos esa primera clase de seguridad sin poner en peligro la libertad general. Se plantean difíciles cuestiones acerca del nivel preciso que de esa manera debe asegurarse; hay, en particular, la importante cuestión de saber si aquellos que así dependerán de la comunidad deberán gozar indefinidamente de las mismas libertades que los demás. Una consideración imprudente de estas cuestiones puede causar serios y hasta peligrosos problemas políticos; pero es indudable que un mínimo de alimento, albergue y vestido, suficiente para preservar la salud y la capacidad de trabajo, puede asegurarse a todos" (Hayek, 1944:144). 
Por su parte, Milton Friedman (1912-2006) popularizó la propuesta del "impuesto negativo a los ingresos". Proponía pagar la diferencia entre los ingresos de otras fuentes y aquel garantizado como "mínimo". La idea básica del INR es que el Estado transfiera dinero a los ciudadanos a través del impuesto sobre la renta, y así garantizarles unos ingresos mínimos. Van Parijs (citado por Lo Vuolo, 1995:46) recuerda que el impuesto negativo a los ingresos propuesto por Milton Friedman no solo se consideraba a un nivel muy bajo, sino que también pretendía ser un instrumento de transición cuyo objetivo final era terminar con las instituciones del Estado de Bienestar.

Vale la pena recordar aquí que hacia finales de 2001 el gobierno nacional creó el Sistema Integrado de Protección a la Familia (SIPROF DNU 1.382/01), el cual según su primer artículo estaba "basado en los principios de solidaridad, igualdad, universalidad e inmediatez, que cubrirá las contingencias de infancia y vejez", separando consecuentemente las Asignaciones familiares de la condición laboral. Sin embargo, este sistema no llegó a implementarse. Por esta razón, el ex ministro de economía Cavallo y uno de los principales actores de la hegemonía y colapso neoliberal en Argentina se adjudica la idea de la $\mathrm{AUH}^{7}$. También, vale la aclaración, dicha medida propuesta en 2001 tenía como finalidad reducir la carga de gasto social destinado a las asignaciones familiares y buscaba eliminar las asignaciones vinculadas al salario por una prestación mucho más focalizada.

\footnotetext{
${ }^{7}$ Entrevista a Domingo Cavallo, "Nosotros en realidad decretamos la AUH en octubre de 2001. Cuando yo presenté la reestructuración de la deuda, el $1^{\circ}$ de noviembre de 2001, la que comenzó la reunión fue Patricia Bullrich, ministra de Trabajo, y explicó el decreto por el cual se creaba el "Salario Familiar Universal", otro nombre para la AUH. El decreto extendía el salario familiar, que por entonces estaba limitado a los trabajadores formales, a todos los trabajadores, con la condición de que el chico fuera a la escuela y se hiciera una revisión médica cada cierto tiempo. Lamentablemente, por razones que yo todavía no entiendo, De la Rúa le pidió la renuncia a Patricia Bullrich y nombró a un dirigente radical, cuyo nombre no recuerdo [N. de la R.: se refiere a José Dumón]. Obviamente, el nuevo ministro no se preocupó por implementar aquella AUH. Pero, en fin, la idea de la AUH me parece que es una buena idea. Y bueno, este gobierno la lanzó, aunque, como con todas las cosas, en lugar de establecerla por ley, con las precauciones necesarias para que sea transparente y llegue a todos los que la necesitan, lo hizo por decreto y con un espíritu político-partidista. Así y todo, el hecho de que exista la AUH me parece una muy buena medida" (Iglesias Illa, H., "Mucho de lo que hoy se critica de los 90 un día será reivindicado", La Nación, 12/2/2012).
} 
De Prácticas y discursos/ Universidad Nacional del Nordeste/ Centro de Estudios Sociales

En este sentido, podemos destacar cómo desde una mirada neoliberal predomina un abordaje focalizado y residual, que concibe a las acciones del Estado desde un papel marginal y compensatorio. Y que aunque parezca que las consecuencias de las reformas socioeconómicas de libre mercado impulsadas conduzcan a un reconocimiento de diversas manifestaciones de la cuestión social vía la asistencia, ello no implica que se suspendan los supuestos ideológicos fundamentales de dicho modelo.

\section{Rousseau, Marx y la igualdad}

A priori es posible pensar que una propuesta redistributiva que proponga una mayor igualdad entre los ciudadanos tiene una mayor afinidad con las tradiciones de izquierda que centraron su preocupación en torno a la igualdad. Desde que la Revolución francesa declarara que "todos los hombres nacen libres e iguales", se ha abierto una contradicción decisiva entre la afirmación de la igualdad fundamental de todos y las inequidades sociales reales.

Desde el desarrollo de la modernidad resultaba claro para muchos que, sin intervención pública y sin un proyecto social capaz de atenuar esos mecanismos desiguales, las sociedades democráticas no sobrevivirían a la cuestión social y a las heridas inferidas por el funcionamiento de un capitalismo sin contenciones (Dubet, 2014).

Jean-Jacques Rousseau (1712-1778) fue de los pensadores de la ilustración quien más reparó en la desigualdad social y en el peso de los derechos para contrarrestar las inequidades. Firme partidario de gravar las grandes fortunas, al creer que la cohesión social pasaba por propiciar una clase media y así erradicar simultáneamente la indigencia y la opulencia. Nadie debería ser tan rico como para poder comprar a otros, ni tan pobre como para caer en la tentación de venderse, sostenía en su Contrato Social (Aramayo, 2015). 
De Prácticas y discursos/ Universidad Nacional del Nordeste/ Centro de Estudios Sociales

Rousseau en su Discurso sobre el origen y los fundamentos de la desigualdad entre los hombres -publicado en 1755- parte de considerar el estado de naturaleza del hombre como una hipótesis o experimento mental que le permite llevar a cabo su reflexión. Su hombre natural es opuesto al planteado por Hobbes, es considerado un "buen salvaje", bueno por naturaleza que posee libre albedrío, compasión, piedad y busca la perfección. La propuesta de Rousseau no es la vuelta a un estado de naturaleza, sino propiciar una profunda reflexión sobre el estado en que se encuentra el hombre.

Su preocupación se centra en las desigualdades que oprimen al hombre: "Considerando la sociedad humana con mirada tranquila y desinteresada, me parece que no se descubre en ella otra cosa que la violencia de los poderosos y la opresión de los débiles" (1955:21). Para Rousseau, existen: "dos clases de desigualdades: la una que considero natural o física, porque es establecida por la naturaleza y que consiste en la diferencia de edades, de salud, de fuerzas corporales y de las cualidades del espíritu o del alma, y la otra que puede llamarse desigualdad moral o política, porque depende de una especie de convención y porque está establecida o al menos autorizada, por el consentimiento de los hombres. Esta consiste en los diferentes privilegios de que gozan unos en perjuicio de otros, como el de ser más ricos, más respetados, más poderosos o de hacerse obedecer" (1955:22).

El origen de estas desigualdades lo sitúa en el surgimiento de la propiedad privada que sí impone como derecho por encima de otros: "El primero que, habiendo cercado un terreno, descubrió la manera de decir: Esto me pertenece, y halló gentes bastante sencillas para creerle, fue el verdadero fundador de la sociedad civil ¡Qué de crímenes, de guerras, de asesinatos, de miserias y de horrores no hubiese ahorrado al género humano el que, arrancando las estacas o llenando la zanja, hubiese gritado a sus semejantes: 'Guardaos de escuchar a este impostor; estáis perdidos si olvidáis que los frutos pertenecen a todos y que la tierra no es de nadie!'"(1955:57). 
De Prácticas y discursos/ Universidad Nacional del Nordeste/ Centro de Estudios Sociales

De ahí que su propuesta sea un "Contrato social" que: "en lugar de destruir la igualdad natural, el pacto fundamental sustituye, por el contrario, con una igualdad moral y legítima lo que la Naturaleza había podido poner de desigualdad física entre los hombres y que, pudiendo ser desiguales en fuerza o en talento, advienen todos iguales por convención y derecho" (El contrato social; 1955:53).

Desde esta perspectiva, si se les saca a los ricos para darle a los pobres, es menos en nombre de una obligación ética hacia los pobres que en función de una unidad de la vida social y de las obligaciones de la "solidaridad orgánica". Afirma en sus Discursos...: “¿Ignoráis por ventura que una multitud de vuestros hermanos perecen o sufren faltos de lo que a vosotros sobra, y que os era preciso un consentimiento expreso y unánime del género humano para que pudieseis apropiaros, de la subsistencia común, todo lo que no teníais necesidad para la vuestra?" (1955:71).

A su vez, el contrato social sirve para contrarestar las injusticias sociales producto de las desigualdades de poder que emanan de la doctrina de la propiedad privada: "el rico, constreñido por la necesidad, concibió al fin el proyecto más arduo que haya jamás realizado el espíritu humano: el de emplear en su favor las mismas fuerzas de los que lo atacaban, de hacer de sus adversarios sus defensores, de inspirarles otras máximas y de darles otras instituciones que le fuesen tan favorables a él como contrario le era el derecho natural". (1955:71)

Posteriormente, será Marx quien realice una crítica inmanente del sistema capitalista y de su lógica intrínseca que genera y necesita de la desigualdad entre los hombres. Desde Marx, los reclamos por la igualdad de la clase trabajadora no son solo porque los individuos sean naturalmente iguales, sino sobre todo porque los trabajadores contribuyen a la producción de la riqueza y del bienestar colectivo y, por eso, la sociedad les debe algo. Con Marx se devela la lógica de explotación del sistema capitalista y cómo la clase dominante se apropia de un plusvalor a costa de la clase trabajadora. 
Si bien Marx luchaba por una revolución de la clase trabajadora que aboliera el capitalismo e instaurara el comunismo, poco dijo sobre cómo pensaba que se organizaría la sociedad del futuro. De ahí la relevancia de la Crítica al Programa de Gotha. Se conoce con ese título a una serie de notas críticas que Marx realizó del programa que en 1875 unificó a los socialistas alemanes en un congreso realizado en la ciudad de Gotha (Tarcus, 2014).

El autor plantea que el derecho burgués resulta inevitable en la primera fase de la sociedad comunista y que solo se resolverá en una fase ulterior: "En la fase superior de la sociedad comunista, cuando haya desaparecido la subordinación esclavizadora de los individuos a la división del trabajo, y con ella, la oposición entre el trabajo intelectual y el trabajo manual; cuando el trabajo no sea solamente un medio de vida, sino la primera necesidad vital; cuando, con el desarrollo de los individuos en todos sus aspectos, crezcan también las fuerzas productivas y corran a chorro lleno los manantiales de la riqueza colectiva, solo entonces podrá rebasarse totalmente el estrecho horizonte del derecho burgués, y la sociedad podrá escribir en su bandera: ¡De cada cual, según sus capacidades; a cada cual, según sus necesidades!” (Marx, 2014: 346-347). Este criterio de justicia social inspiraría notablemente a las tradiciones de izquierda.

Aunque Marx consideraba que: "es equivocado, en general, tomar como esencial la llamada distribución y hacer hincapié en ella, como si fuera lo más importante. La distribución de los medios de consumo es, en todo momento, un corolario de la distribución de las propias condiciones de producción" (2014:347). Y que "el socialismo no puede acabar con la miseria, determinada por la misma naturaleza, sino solo generalizarla, repartirla por igual sobre toda la superficie de la sociedad!" (2014:351). Esta crítica de una distribución secundaria del ingreso se basa en su apuesta por la abolición de las relaciones materiales de producción. A pesar de esto, sus planteos resultan insoslayables en las tradiciones políticas que luchan por una mayor igualdad y en cualquier discusión sobre una sociedad justa. 
La influencia tanto de Rousseau como de Marx es posible encontrarlas en dos perspectivas que participan del debate en torno a la $\mathrm{AUH}$. Me refiero a las discusiones vinculadas al "Ingreso Ciudadano Universal" y al conocido como "enfoque de derechos humanos".

El debate sobre el Ingreso Ciudadano ${ }^{8}$ (IC) surgió en Argentina a mediados de la década de los noventa, de la mano de un grupo de intelectuales que consideraba pertinente su aplicación dada la realidad de entonces (Lo Vuolo y otros, 1995). Dicha propuesta sugería como prueba anterior instaurar un Ingreso Ciudadano a la Niñez ${ }^{9}$ Se sostenía que desde distintas tradiciones de filosofía política se podía apoyar una medida como el IC, tanto desde el liberalismo igualitarista como desde el comunismo y el comunitarismo. Uno de los elementos normativos del IC radica en un supuesto "derecho a la existencia", que fuera enunciado por primera vez por Robespierre en un discurso de 1794, donde expresó que la sociedad debe garantizar a todos sus miembros, como primer derecho, el de existir material y socialmente.

La propuesta generó una discusión particular relacionada con su potencialidad para hacer efectivos ideales defendidos por distintos proyectos emancipatorios, incluyendo el comunismo. Autores como Van der Veen y Van Parijs (1987) incluso llegaron a sostener que con esta propuesta se propiciaría "Una vía capitalista al comunismo". La propuesta va más allá de una simple recomendación redistributiva, en tanto establece un vínculo fuerte entre el IC y la posibilidad de un cambio radical en la sociedad. Al

\footnotetext{
${ }^{8}$ El gobierno nacional en 2007 (previo a la AUH) se manifestaba en contra del IC en un documento del Ministerio de Desarrollo Social: "Esta propuesta, que no compartimos, no está centrada en la búsqueda del pleno empleo, o el combate al desempleo, sino en el otorgamiento de un subsidio universal o ingreso básico, también conocido como Ingreso Ciudadano, garantizado a todos los habitantes, por el solo hecho de ser ciudadanos o residentes. Esta modalidad no toma en cuenta si la persona está desocupada, ya que si se le quiere dar el carácter de universal, alcanzaría incluso a quienes no buscan trabajar, y sin diferenciar tampoco si es rico o pobre o con quién conviva" (La Bisagra, documento del Ministerio de Desarrollo Social nacional, Dra. Alicia Kirchner, 2007).

${ }^{9}$ El principal antecedente que reconoce la idea de aplicar un ingreso de ciudadanía integrado a una reforma tributaria lo constituye un proyecto de ley presentado en 1997 por Elisa Carca y Elisa Carrió, por entonces diputadas nacionales de la Unión Cívica Radical (UCR). El proyecto disponía la creación de un "Ingreso Ciudadano para la Infancia" (INCINI), consistente en el pago directo y en dinero de un ingreso, en cabeza de la madre, a todos los menores desde el cuarto mes del embarazo y hasta los 18 años de edad.
} 
De Prácticas y discursos/ Universidad Nacional del Nordeste/ Centro de Estudios Sociales

sintetizar los planteos de Van der Veen y Van Parijs, argumentan que la justificación del socialismo como vía al comunismo se sostiene sobre dos imperativos fundamentales: 1) es necesario fomentar el altruismo, liberando al hombre del egoísmo propio del sistema capitalista; 2) es necesario el máximo de productividad, superando la escasez, y esto solo puede obtenerse mediante la propiedad colectiva de los medios de producción. Para los autores, el comunismo no necesita del altruismo, y la sociedad capitalista ha demostrado tener capacidad para generar una fuente de desarrollo productivo. De ahí que rescaten del comunismo el principio "de cada uno según sus capacidades, a cada uno según sus necesidades"; para ellos, esta situación podría alcanzarse sin pasar previamente por el socialismo, con un sistema institucional que incluya medidas como el IC.

Otra de las tradiciones desde la cual se valora y discute a la AUH remite a lo que se conoce como "enfoque de derechos humanos". Refiere a una perspectiva garantista de los derechos humanos que plantea la exigibilidad de los derechos económicos, sociales y culturales al ser estos de igual naturaleza que los derechos civiles y políticos, y por lo tanto susceptibles de demandar acciones positivas del Estado. Una de las principales discusiones en los últimos años en Argentina se vincula con los nexos entre políticas sociales y derechos sociales (Abramovich y Courtis, 2006), y especialmente con la reconstrucción de las políticas sociales en clave de derechos sociales, en particular, a la luz de la integración creciente entre las fuentes nacionales de desarrollo de tales derechos y los aportes del sistema internacional de derechos humanos (Abramovich y Pautassi, 2009). Esta perspectiva anclada en los derechos humanos se opone a los planteos teóricos y las prácticas institucionales que, particularmente en la década de 1990, redujeron la discusión sobre política social a medidas puntuales de "lucha contra la pobreza".

Siempre que se hace referencia al denominado "enfoque de derechos" aplicado a las estrategias de desarrollo, se considera el amplio conjunto de principios, reglas y estándares que integran los derechos humanos fundamentales, y que son pasibles de 
De Prácticas y discursos/ Universidad Nacional del Nordeste/ Centro de Estudios Sociales

ser aplicados para establecer pautas y criterios para el diseño e implementación de estrategias de desarrollo sustentable y con mayor interés aún en materia de políticas sociales (Abramovich y Pautassi, 2009). Estas pautas, que se traducen en estándares jurídicos -como la obligación de garantizar el contenido mínimo de los derechos, la obligación para los Estados de no aplicar políticas regresivas sino progresivas, la obligación de garantizar la participación ciudadana- y también en principios -el principio de igualdad y no discriminación, universalidad; acceso a la justicia, acceso a la información pública- se utilizan para desarrollar una matriz útil en la definición de las políticas y estrategias de intervención tanto de los Estados como de los actores sociales y las agencias de cooperación para el desarrollo, como también para el diseño de acciones para la fiscalización y evaluación de políticas públicas (Pautassi, 2012). Muchas de las producciones sobre la AUH se basan en los indicadores sobre derechos sociales que surgen desde esta perspectiva. A partir de allí, se definen los avances y los aspectos pendientes de las políticas sociales. Incluso quienes se sitúan en esta perspectiva no encuentran consideraciones homogéneas sobre el carácter de derechos de la AUH, las posiciones varían como mencionábamos anteriormente, según como son interpretados los distintos elementos presentes.

En este sentido, ninguna perspectiva teórica está ajena a las disputas que se presentan en el espacio social en torno a la definición de lo público. Por esto, el campo de las políticas sociales es un campo atravesado por una doble disputa: teórico-conceptual y político-institucional (Danani, 2004).

\section{La recuperación de una idea de Estado}

Una forma de lograr una mejor comprensión del proceso de recuperación de la centralidad del Estado iniciado en Argentina, en 2003, lo encontramos volviendo a los planteos clásicos de Hegel en su tratado sobre Filosofía del derecho. Recuperar a Hegel es volver a leer a un autor con notable influencia en las tradiciones de izquierda en América Latina, fundamentalmente en los años sesenta y setenta. Su influencia sigue 
De Prácticas y discursos/ Universidad Nacional del Nordeste/ Centro de Estudios Sociales

presente como significaciones de un Estado que debe representar los intereses colectivos evitando los particularismos.

Para Hegel, hay algo de misterioso en el Estado, principalmente porque al interior del mismo se da una conversión de los intereses particulares en generales. Hegel va a justificar la presencia y la formación del Estado a partir de la preservación de la unidad de la sociedad civil. "La esencia del Estado mismo moderno es que lo universal esté ligado a la libertad completa de la particularidad y al bienestar de los individuos, que, por tanto, el interés de la familia y la sociedad civil tiene que juntarse en el Estado, pero que la universalidad de la finalidad no puede progresar sin el propio saber y querer de la particularidad, la cual tiene que conservar su derecho" (1988:260). Es en el Estado donde la sociedad civil encuentra por fin su unidad. "Todo depende de la unidad de la universalidad y la particularidad en el Estado" (1988:261). El Estado representa los intereses universales, "las determinaciones de la voluntad individual son introducidas por el Estado en una existencia empírica objetiva y solo mediante él llegan a su verdad y realización. El Estado es la única condición de la obtención de la finalidad y del bienestar particulares" (1988:261). Solo a través del Estado es posible la realización del interés individual y la realización de la verdadera libertad. "La idea del Estado en los tiempos modernos tiene la propiedad de que el Estado es la realización de la libertad" $(1988: 260)$.

En el Estado se produce una mediación de lo particular por lo universal, en donde el egoísmo objetivo se transforma en la contribución a la satisfacción de las necesidades vitales de los otros. Esta concepción resulta la base de la propuesta del gobierno de lo que podemos llamar "inclusión social a través del consumo", es decir, que mediante un Estado que regule e intervenga en la actividad económica se garantiza un piso de ingresos y los derechos sociales básicos de la mayoría de la sociedad.

Hegel también planteaba que: "El límite entre el derecho de los padres y el de la sociedad civil es aquí muy difícil de marcar. Con respecto a la educación, los padres 
De Prácticas y discursos/ Universidad Nacional del Nordeste/ Centro de Estudios Sociales

piensan habitualmente tener plena libertad y poder hacer todo aquello que quisieran. En el ámbito de todo lo público de la educación la oposición principal proviene habitualmente de los padres, y ellos son los que vociferan y hablan sobre profesores e instituciones por cuanto oponen su antojo a estos. A pesar de esto, la sociedad tiene el derecho de proceder según sus probadas opiniones, a obligar a los padres a enviar a sus hijos a la escuela, a vacunarlos contra la viruela, etc..." (1988:240). Este Estado donde se realiza la libertad puede intervenir en la sociedad civil para realizar un interés universal.

Es interesante recuperar esta cita respecto del debate que se suscita en torno a las condicionalidades de la AUH. La conveniencia o no de establecer condicionalidades en una política de transferencia de ingresos es un debate abierto. Existen diversas posiciones con respecto a este tema. Se sostiene, por un lado, que aún no se ha demostrado acabadamente que la exigencia de condicionalidades sea el mecanismo más eficiente para asegurar responsabilidad y construcción de conciencia de derechos por parte de titulares. Por el contrario, se mantiene que las diferencias establecidas entre los requisitos exigidos a los titulares de la AUH y a titulares del régimen de asignaciones familiares para trabajadores formales -a quienes no se les exigen contraprestaciones- indican la permanencia de criterios que establecen una línea divisoria entre "merecedores" por derecho propio y aquellos que deben comprobar que lo son. Esto influye necesariamente en la percepción que tienen los propios sujetos destinatarios y las instituciones que certifican dichas condiciones. Por otro lado, las críticas apuntan a que se estaría poniendo el foco en el sujeto titular de la política y no en la demanda de los servicios de educación y salud. En este sentido, sería necesario hablar de corresponsabilidades más que de condicionalidades, más a tono con un enfoque de derechos que recupere el rol central del Estado en la prestación de los servicios de salud y educación, poniendo de relieve las dificultades en la oferta y calidad de estos derechos y no solo en la exigencia de las familias en cumplir con estos requisitos. 
De Prácticas y discursos/ Universidad Nacional del Nordeste/ Centro de Estudios Sociales

Algunas posiciones sostienen que las condicionalidades existen como forma de garantizar la aprobación social, ya que supuestamente una mayor parte de la población estaría en contra de transferir recursos incondicionalmente. Otros autores, como Strasachnoy (2015), plantean que las condicionalidades de la AUH se explican en gran medida por los proyectos que surgieron en otros contextos y con otros determinantes, y que debido a un "Pathdependence" se establece una tendencia a reforzar la adopción de políticas con el paso del tiempo. Es decir, que "las decisiones pasadas en relación a una política influyen hacia su continuidad en las decisiones presentes y futuras" (Strasachnoy, 2015:137).

Por mi parte, y volviendo a la cita de Hegel, considero que las condicionalidades responden a un interés positivo del Estado de intervenir en la sociedad civil en los temas de educación y salud. Más allá de los sesgos que bien se le pueden adjudicar a las condicionalidades de un derecho social como la $\mathrm{AUH}$, la realidad federal del país, con su descentralización de los servicios universales de salud y educación -realizados en los noventa- dificulta otras vías para intervenir en las problemáticas de deserción escolar y cobertura sanitaria. Si vemos el accionar del Estado en la última década, y previo a la $\mathrm{AUH}$, el aumento de inversión y de programas de salud y educación da cuenta de una motivación del Ejecutivo nacional por estas realidades.

\section{A modo de cierre}

Hasta aquí se buscó exponer descriptivamente algunos de los conceptos teóricos que subyacen en los actuales debates de la política social argentina. La propuesta expositiva no busca dar por saldado un debate, sino más bien mostrar la amplitud que tiene su actual vigencia. La historia argentina podría pensarse como una serie de debates no saldada aún entre modelos antagónicos de país, entre propuestas liberal conservadoras y reivindicaciones nacionales y populares. En esa historia, una política como la AUH difícilmente alcance una hegemonía tal que permita pensar su superación en un sentido de ampliación de mayores derechos sociales. En este sentido, la disputa por el 
De Prácticas y discursos/ Universidad Nacional del Nordeste/ Centro de Estudios Sociales

alcance de los derechos sociales es una disputa abierta, no es una historia lineal de logros, sino que presenta avances y retrocesos que se vinculan a la vigencia de la democracia, pero también a la capacidad de las instituciones democráticas de incorporar demandas y problematizaciones sociales (Britos, 2003).

En esa clave podemos leer las discusiones parlamentarias de la ley 27.160 que sanciona la movilidad de la AUH. Encontraremos muchos argumentos vinculados a las perspectivas teóricas reseñadas. Sostiene la senadora por Tucumán, Beatriz Rojkés de Alperovich, en la Cámara de Senadores, el 1/07/2015: "Podríamos decir que la AUH se encuentra en el ADN del peronismo. Si me permiten, voy a citar: Pienso que habría que empezar por señalar para cada mujer que se casa una asignación mensual desde el día de su matrimonio. Un sueldo que pague a las madres de toda la nación y que provenga de los ingresos de todos los que trabajan en el país, incluidas las mujeres. Nadie dirá que no es justo que paguemos un trabajo que, aunque no se vea, requiere cada día el esfuerzo de millones y millones de mujeres. Luego podrían añadirse a ese sueldo básico los aumentos por cada hijo, mejoras en caso de viudez, pérdida por ingreso a las filas del trabajo, en una palabra todas las modalidades que se consideren útiles a fin de que no se desvirtúen los propósitos iniciales. Yo solamente lanzo la idea. Será necesario darle forma y convertirla, si conviene, en realidad. Creo que acá tenemos el derecho de autoría: Eva Perón en La razón de mi vida.

En aquel primer gobierno peronista se incorporarían en nuestra legislación todas las reivindicaciones laborales y sociales, entre las que se encuentran el salario familiar y las asignaciones por hijo. Pero quedaba fuera de la protección del Estado el sector más vulnerable: los trabajadores irregulares o los que no tenían empleo".

La disputa sobre la ampliación de los derechos sociales caracteriza a la historia argentina del siglo XX y los comienzos del siglo XXI. Como sostiene García Linera (2015), el Estado es una cotidiana trama social entre gobernantes y gobernados, en la 
De Prácticas y discursos/ Universidad Nacional del Nordeste/ Centro de Estudios Sociales

que todos, con distintos niveles de influencia, eficacia y decisión, intervienen en torno de la definición de lo público, lo común, lo colectivo y lo universal.

Si bien podemos discutir el grado de universalidad de la AUH según criterios de cobertura, el carácter universal de la $\mathrm{AUH}$, como manifestación del interés colectivo, es algo en lo que todos en la actual coyuntura pareciéramos estar de acuerdo.

Pero como ya nos alertaba Gramsci (2004:19).: "Universal no quiere decir absoluto. No hay en la historia nada absoluto ni rígido. Las afirmaciones del liberalismo son ideaslímite que, una vez reconocidas como racionalmente necesarias, se han convertido en ideas-fuerza, se han realizado en el Estado burgués, han servido para suscitar la antítesis de ese Estado en el proletariado y luego se han desgastado. Universales para la burguesía, no lo son suficientemente para el proletariado. Para la burguesía eran ideas-límite, para el proletariado son ideas-mínimo. Y, en efecto, el entero programa liberal se ha convertido en programa mínimo del Partido Socialista. El programa, esto es, lo que sirve para vivir cotidianamente, en espera de que se considere llegado el instante más útil".

De la misma manera, podemos afirmar que una propuesta como la AUH puede ser considerada en tanto idea-límite por los defensores del neoliberalismo. Por el contrario, es una idea-mínima para los sectores populares que tienen conciencia de los derechos que han recuperado y pugnan por avanzar en nuevas conquistas sociales.

\section{Bibliografía}

Abramovich, V. y Courtis, C. (2006). El umbral de la ciudadanía. El significado de los derechos sociales en el Estado social constitucional. Buenos Aires: Editores del Puerto. 
De Prácticas y discursos/ Universidad Nacional del Nordeste/ Centro de Estudios Sociales

Abramovich, V. y Pautassi, L. (2009). La revisión judicial de las políticas sociales. Estudio de casos. Buenos Aires: Editores del Puerto.

Aramayo, R. (2015). Rousseau y la política hizo al hombre (tal como es). Buenos Aires: Ed. Bonalletra Alcompas.

Arcidiácono, P.; Carmona Barrenechea, V. y Straschnoy, M. (2011). La asignación universal por hijo para protección social: rupturas y continuidades, ¿hacia un esquema universal?. Revista Margen, 61.

Baschet, J. (2014). Adiós al capitalismo. Autonomía, sociedad del buen vivir y multiplicidad de mundos. Buenos Aires: Ed Futuro anterior/NED.

Britos, N. (2003). La trayectoria de la ciudadanía en Argentina. Derechos humanos y ciudadanía. En Aquín, N. (comp.) Ensayos sobre ciudadanía. Reflexiones desde el Trabajo Social. Buenos Aires: Editorial Espacio.

Costa, M. I. y Hintze, S. (2014). Capacidad protectora de la Asignación Universal por Hijo para Protección Social: problemas y debates a cuatro años de su implementación. En Danani C. y Hintze S. (coord.) Protecciones y desprotecciones (II): problemas y debates de la seguridad social en la Argentina. Argentina: Ed. Los Polvorines, Universidad Nacional de General Sarmiento.

Danani, C. (1996). Algunas precisiones sobre la política como campo de estudio y la noción de población-objeto. En AA.VV. Políticas Sociales. Contribución al debate teóricometodológico. Buenos Aires: Ediciones Universidad de Buenos Aires.

Danani, C. y Beccaria, A. (2011). La (contra) reforma previsional argentina 2004-2008: aspectos institucionales y político-culturales del proceso de transformación de la protección. En Danani, C. e Hintze, S. (coord.) Protecciones y desprotecciones: la 
De Prácticas y discursos/ Universidad Nacional del Nordeste/ Centro de Estudios Sociales

seguridad social en la Argentina 1990-2010, Capítulo 3. Argentina: Ed. Universidad Nacional de General Sarmiento.

Dubet, F. (2014). Repensar la justicia social. Contra el mito de la igualdad de oportunidades. Buenos Aires: Ed. Siglo Veintiuno.

Esping-Andersen, G. (1993). Los tres mundos del Estado de Bienestar. Valencia, España: Edicions Alfons el Magnanim.

García Linera, A. (2015). El Estado y la vía democrática al socialismo. Revista Nueva Sociedad, 259. Buenos Aires: Ed Nueva Sociedad.

Grassi, E. y Danani, C. (2008). Ni error, ni omisión. El papel de la política de Estado en la producción de las condiciones de vida y de trabajo. El caso del sistema previsional en la Argentina (1993-2008). En Lindenboim, J. (comp.) Trabajo, ingresos y políticas en Argentina. Contribuciones para pensar el siglo XXI. Buenos Aires: EUDEBA.

Gramsci A. (2004). Antología. Volumen 1: "Tres principios tres ordenes". Buenos Aires: Editorial Siglo XXI.

González, C. (2012): Nuevas tendencias del Sistema de Protección Social en Argentina en el nuevo milenio: ¿hacia un nuevo paradigma? Revista Textos \& Contextos, Vol. 11. Porto Alegre.

Hayek, F. (2008). Camino de servidumbre. Disponible en: http://www.elcato.org/sites/default/files/camino-de-servidumbre-libro-electronico.pdf

Hegel, G. W. F. (1988). Principios de la filosofía del derecho. Barcelona: Ed. Edhasa. 
De Prácticas y discursos/ Universidad Nacional del Nordeste/ Centro de Estudios Sociales

Hintza S. (2015). La Asignación Universal por Hijo en el marco de la política y la seguridad social en Argentina. Revista Debate público. Reflexiones de Trabajo Social. $\begin{array}{llll}\text { Buenos } & \text { Aires: } & \text { Ud } & \text { Disponible }\end{array}$ http://trabajosocial.sociales.uba.ar/publicaciones.htm

Laurell, A. C. (2000). Avanzar al pasado: la política social del neoliberalismo. En Borgianni, E. y Montaño, C. (orgs.) La política social Hoy. Brasil: Cortez Editora.

Lo Vuolo, R. (1995). Contra la Exclusión. La propuesta del Ingreso Ciudadano. Buenos Aires: Ciepp/Miño y Dávila Editores.

Lo Vuolo, R. (2010). Las perspectivas de ingreso ciudadano en América Latina. Un análisis en base al 'Programa Bolsa Familia' de Brasil y a la 'Asignación Universal por Hijo para Protección Social' de Argentina. Documento de Trabajo, 75. CIEPP.

Marx K. (2014). Antología: "Crítica al Programa de Gotha". Buenos Aires: Editorial Siglo XXI.

Mill, J. S. (2004). Sobre la Libertad. Barcelona: Alianza Editorial.

Mazzola, R. (2012). Nuevo paradigma. La Asignación Universal por Hijo en la Argentina. Buenos Aires: Ed. Prometeo.

Nozick, R. (1988): Anarquía, Estado y utopía. México: Fondo de Cultura Económica.

Observatorio de la Seguridad Social-ANSES (2012). La Asignación Universal por Hijo para Protección Social en perspectiva. La política pública como restauradora de derechos. Consultado el 14/02/13. Disponible en: http://observatorio.anses.gob.ar/files/subidas/OBS\%20-\%2000265\%20\%20AUH\%20en\%20Perspectiva.pdf 
De Prácticas y discursos/ Universidad Nacional del Nordeste/ Centro de Estudios Sociales

Pautassi, L. (2012): Desigualdad revisitada. Vulnerabilidad, protección y Derechos. Revista Escenarios, 18. Facultad de Trabajo Social UNLP.

Rousseau, J. J. (1992). Del contrato social-Discursos. Madrid: Alianza.

Straschnoy, M. (2015). ¿Para qué y por qué se implementan las condicionalidades en la Política Social Argentina? Revista Debate público. Reflexiones de Trabajo Social. Argentina: Ed. UBA. Disponible en: http://trabajosocial.sociales.uba.ar/publicaciones.htm

Tarcus H. (2014). Introducción. Leer a Marx en el siglo XXI. En Marx K. Antología: "Crítica al Programa de Gotha". Buenos Aires: Editorial Siglo XXI.

Tirenni, J. (2013). La política social argentina ante los desafíos de un Estado inclusivo (2003-2013). Revista Estado y Políticas Públicas, 1.

Torrice, L. e Iriarte, N. (2014, abril). La seguridad social en el centro de la política social argentina. Un recorrido por los últimos treinta años de democracia. Revista Debate público. Reflexiones de Trabajo Social, 7. Argentina: Ed. UBA, p. 85. Disponible en: http://trabajosocial.sociales.uba.ar/publicaciones.htm

Van der Veen, R y Van Parijs, P (1987). Una vía capitalista al comunismo. Revista Zona Abierta, 46-47. 